\title{
ENHANCEMENT OF BID DECISION-MAKING IN CONSTRUCTION PROJECTS: A RELIABILITY ANALYSIS APPROACH
}

\author{
Farzad GHODOOSI ${ }^{1}$, Ashutosh BAGCHI ${ }^{1}$, M. Reza HOSSEINI (12*, \\ Tatjana VILUTIENE் ${ }^{3}{ }^{3}$, Mehran ZEYNALIAN ${ }^{4}$ \\ ${ }^{1}$ Department of Building, Civil and Environmental Engineering, Concordia University, Montreal, Canada \\ ${ }^{2}$ School of Architecture and Built Environment, Deakin University, Geelong, 3220 Victoria, Australia \\ ${ }^{3}$ Department of Construction Management and Real Estate, Faculty of Civil Engineering, Vilnius Gediminas \\ Technical University, LT-10223 Vilnius, Lithuania \\ ${ }^{4}$ Department of Civil Engineering, University of Isfahan, Isfahan, Iran
}

Received 23 April 2020; accepted 5 January 2021

\begin{abstract}
Various risks significantly influence pricing of bids and a wide range of factors impact bid pricing risks. Of these, client's reputation and the record of projects owned by a client have vital contribution on the issue. Current practices however fail to capture the impacts of client-related factors. There is a need for developing a practical quantitative approach, which enables estimators to process bid risk allocation easily. Through reliability analysis, the developed method proposed in this study enables practitioners to make informed bid/no-bid decisions based on estimating the probabilities of schedule and cost overruns. Estimating the probability of project failure enables estimators to quantify the risk element of bid price. In addition, schedule and cost overrun cumulative probability distributions can be used to estimate the expected value of these variables. The practicability of this proposed method is tested by empirical data obtained from 40 university construction projects of one client, for estimating the bid price of a low-rise building. For researchers, findings provide illuminating insight into the potential of using reliability analysis as a valuable tool for bid decision-making practices. So too, the proposed method offers a blueprint for estimating and calculating time and contingency - and managing associated risks - in planning construction projects. The contribution of this study for the world of practice lies in providing a simple, rapid and cost-effective method for bid decision-making processes.
\end{abstract}

Keywords: bid decision-making, reliability analysis, tender, contingency, risks, construction procurement.

\section{Introduction}

For about $86 \%$ of projects in the global market, about 8.7 trillion dollars are spent on public bidding, for allocating projects to contractors (Leśniak, 2015; Ballesteros-Pérez \& Skitmore, 2016). Contractors worldwide face the challenging task of bid decision-making and offering a bid price high enough to generate a decent profit and low enough to win the bid (Asgari et al., 2016). This process involves several steps of preparing quantity take-off, cost estimation, risk allocation, bid preparation, price negotiation and reaching an agreement. Moreover, the final decision regarding a project is heavily influenced by assumptions on uncertainties of the project (Duzkale \& Lucko, 2016b). Bid decision-making is essential to the business health of contractors, given that this is the main mechanism of allocating projects to contractors in the construction context (Asgari et al., 2016; Su et al., 2020). Despite such importance, a review run on the literature reveals major deficiencies and drawbacks in current bid decision-making practices of the construction industry (Owusu et al., 2020), as discussed below.

First, bid decision-making requires an accurate incorporation of risks into the decision-making process (Laryea \& Hughes, 2011; Duzkale \& Lucko, 2016a). This requirement is overlooked in current bid decision-making practices (Leśniak \& Plebankiewicz, 2015). That is, depending on the nature of a project, contractors typically consider a risk margin of $1-10 \%$ of the estimated cost intuitively (Laryea \& Hughes, 2008, 2011). Second, the entire bid decision making process is typically completed subject to tight scheduling, over a short period of time,

*Corresponding author. E-mail: reza.hosseini@deakin.edu.au 
when collecting necessary data is difficult and, on some occasions, impracticable (Ballesteros-Pérez et al., 2013). Consequently, relying on past experiences, intuition, gut feelings, guesses, and verbal instructions of Chief Executive Officers (CEOs) - as the main actors in bid decisionmaking - is common (Ye et al., 2014; Leśniak \& Plebankiewicz, 2015; Hwang \& Kim, 2016). Use of innovative analytical methods including artificial intelligence is time consuming, given their steep learning curve - sometimes impractical due to their complexity for ordinary practitioners of the construction industry (Laryea \& Hughes, 2011; Ballesteros-Pérez et al., 2014). Common analytical models are too complicated for estimators and managers (Laryea \& Hughes, 2011) and require massive data inputs and advanced mathematical apparatus. These problems make construction practitioners reluctant to apply them in their day-to-day operations (Laryea \& Hughes, 2011; Ballesteros-Pérez et al., 2014). Modern methods like Building Information Modelling (BIM) that assist contractors in bid decision-making require specific skillsets, where costs might not be justified for contractors, particularly small businesses (Elghaish et al., 2020). Consequently, commonly used bid decision-making practices lack reliability and accuracy. These processes remain overly complex and based on intuition, subjective judgement and experience (Chileshe et al., 2020). This exposes contractors to a wide range of damaging consequences, including the possibility of driving contractors into bankruptcy (Sonmez \& Sözgen, 2017; Yazdani et al., 2019).

Studies on bid decision making for the most part have focused on selecting the most important factors; conducting interviews with experts to explore relationships among influential factors; or designing bid decision making models using different techniques (Aznar et al., 2017). Few studies have attempted to develop workable, systematic methods for bid decision-making (Sonmez \& Sözgen, 2017). Subsequently, there is need for a workable bid decision-making solution that overcomes the deficiencies discussed above, and enhances the accuracy of bid pricing (Ballesteros-Pérez \& Skitmore, 2016; Sonmez \& Sözgen, 2017). According to Li et al. (2020), bid decision-making requires complex maldistributed analysis, for which there exists no comprehensive simple analytical methods. And construction practitioners remain largely unaware and unsupportive of existing bid decision-making tools (Urquhart \& Whyte, 2018). This is study is an attempt to fill the identified gap.

The primary objective here is to propose a systematic, objective and accurate bid decision-making analytical framework that incorporates risks and is also comprehensible and practical to be used by ordinary construction contractors, with no need for specific analytical tools and skillsets. Findings add value to the exiting body of knowledge on bid decision making. The study provides researchers with another analytical tool for decision-making procedures; an accurate systematic procedure founded on reliability analysis is also offered to the field for estimating and calculating contingency in construction projects.
So too, findings discussed here will be of direct appeal to a wide range of construction practitioners. Particularly, estimators, planners and managers will benefit from the findings in dealing with competitive public biddings.

\section{Background}

\subsection{Bid decision making process}

Bid decision making triggers significant implications for the current state and the future of construction companies (Leśniak \& Plebankiewicz, 2015; Asgari et al., 2016). Construction companies typically survive and expand their business volume through successful bidding on available projects (Egemen \& Mohamed, 2007; Chou et al., 2013). Due to its importance, since 1950, a rich body of literature is devoted to assess various features associated with contractors' bid decision-making practices (Chou et al., 2013). Bid decision-making process for contractors encompasses two overlapping stages of deciding whether to bid or not, and if yes then calculate the bidding price (Egemen \& Mohamed, 2007; Awwad, 2016; Biruk et al., 2017). These two overlapping stages are interrelated with bidding price calculation as a highly influential factor in making bid/ no-bid decision; bidding price defines expected profits and a company's position in terms of competition (Chua \& Li, 2000; Biruk et al., 2017). The bidding price makes it clear whether the contractor has the ability and resources to carry out such a project (Leśniak \& Plebankiewicz, 2015). As argued by Biruk et al. (2017) bidding price is a determinant of project attractiveness, in linear correlation with contract desirability, thus manipulating bid/no-bid decisions. Therefore, improving biding price practices sits at the center of decisions about a bid (Awwad \& Ammoury, 2019); bid pricing is the dimension of bid decision-making explored in this study, a description of which follows.

\subsection{The bidding price}

A review run on the literature reveals that available studies for the most part focus on developing effective models to facilitate decision making in bidding, through different analytical methods and techniques (Leśniak \& Plebankiewicz, 2015). Some researchers have highlighted the value of intuition and experience. As an example, Chua et al. (2001) and $\mathrm{Hu}$ et al. (2016) refer to case-based reasoning bidding, as a subbranch of artificial intelligence that solves new problems by matching against similar problems. A variety of other tools and techniques are suggested for handling bid decision making. These include statistical methods (Carr, 1982); neural networks (Wanous et al., 2003); multi-attribute decision making approaches (Cheng et al., 2011; Chou et al., 2013); data envelopment analysis (ElMashaleh, 2010); linear programming (Biruk et al., 2017); artificial-intelligence-oriented techniques (Chao, 2007); probability graphs (Ballesteros-Pérez et al., 2013); and support vector machine (Sonmez \& Sözgen, 2017) among others. Adopting these methods on the contractors' part is time consuming and sometimes even impractical due to 
their complexity for construction practitioners (Laryea \& Hughes, 2011; Ballesteros-Pérez et al., 2014).

Recently, with the emergence of BIM in the construction industry, there is growing interest in calculating the cost of projects, using 5D BIM (Alsharqawi, 2016; Elghaish et al., 2020). That said, BIM implementation is fraught with many challenges including lack of skilled employees, steep learning curve and issues of set up cost and investment, particularly for smaller businesses, which make up a major part of the construction industry (Hosseini et al., 2016).

Calculating the bidding price for contractors typically is of two phases: estimating the actual project costs and adjudication, that is, applying market conditions (Laryea \& Hughes, 2011). As defined by Kitchenham et al. (2003), bid price is obtained through Eqn (1):

Bid Price $=$ Estimated Total Cost + Costs of Risks + Profit.

The estimated total cost of a project includes direct and indirect costs. Direct cost is derived from tender documents and drawings by calculating the quantities and the corresponding costs of required project resources (material, labor, machinery, etc.). Evidence indicates that cost estimations might be somewhat inaccurate due to the time pressure factor (Ye et al., 2014) accompanied with ambiguity and lack of details in tender documents (Laryea \& Hughes, 2011).

The amount of profit depends on the return a contractor expects from the project, often factored in as a percentage of calculated costs. In case winning the tender is vital for the contractor, experts decide to reduce the profit level in order to increase the chance of success (Ling \& Liu, 2005; Ye et al., 2014). Still more, when winning is critical to a contractor, profit might be adjusted, even by a negative factor (Ye et al., 2014). Consequently, contractors increase the chance to win the tender following by adopting mechanisms to recover potential losses (Kitchenham et al., 2003; Laryea \& Hughes, 2011). This process is risky, full of uncertainties and requires close consideration of current market state of affairs, competitiveness level, information of opponents and financial circumstances of the company and the client; hence, a very complex and multidimensional decision-making process (Awwad, 2016). These parameters make the importance of accurate incorporation of risks and uncertainties in bidding pricing processes outstanding (Ye et al., 2014; Shokri-Ghasabeh \& Chileshe, 2016); thus, justifying the application of reliability analysis approach, as discussed next.

\subsection{Reliability analysis}

Stochastic analysis-based methods are widely challenged in view of the limited knowledge on the high-consequence real-life problems context, where available information cannot provide a strong basis for probability assignment (Aven \& Zio, 2011; Johansson et al., 2013). To encounter this issue, reliability analysis has emerged to provide infor- mation in decision-making processes in practice, where a certain amount of known and unknown risks are involved (Singh et al., 2007). As defined by Zio (2009, p. 126) "the objective of reliability analysis is to quantify the probability of failure of the system and its protective barriers." Reliability analysis, as a practical decision-making technique, reflects on the state of knowledge for the treatment of uncertainties in risk assessments (Aven \& Zio, 2011). This method has become one of the most common methods in quantifying risks and an effective tool to provide an image of a complex system's likely behavior affected by a wide range of factors and uncertainties (Tung et al., 2006; Johansson et al., 2013). The reliability analysis method is based on the limit state function defined through Eqn (2):

$$
g=R-Q,
$$

where $Q$ is the statistical variable representing external forces or demands and $R$ is the resistance (capacity, or supply). In this method the safety margin of the system is described by the reliability index $\beta$, as defined in Eqns (3) and (4):

$$
\begin{aligned}
& \beta=-\Phi^{-1}\left(P_{F}\right) ; \\
& P_{F}=P(g<0),
\end{aligned}
$$

where, $P_{F}$ is the probability of system failure and $\Phi^{-1}$ is the cumulative standard normal distribution function inverse; thus, the probability of failure is presented as Eqn (5):

$$
P_{F}=\Phi(-\beta) \text {. }
$$

\section{Research methods}

Reliability is defined as the probability of no failure where failure is associated with intended objectives of a decisionmaking process (Singh et al., 2007). For contractors, a project is failed when it faces cost or schedule overruns, hence a failure in meeting the desired objectives of the contractor and the owner/client (Russell \& Jaselskis, 1992). With reference to Eqn (2), $Q$ is the cost or time where a project is actually accomplished and $R$ represents the agreed cost or time mentioned in the contract or bid. This perspective provides estimators and managers with a new approach to manage bid decision-making based on estimating the probabilities of schedule and cost overruns with respect to the records of the accomplished projects (Galway, 2004). Bidding price is significantly affected by owner's reputable record of past projects (Ye et al., 2014; Shokri-Ghasabeh \& Chileshe, 2016). Such a record reflects the financial condition of the owner, likelihood of obtaining a guarantee of payment, and the level of the bid bond; these are all effective in calculating costs (Laryea \& Hughes, 2008). Irregular payments, frequent change orders and delayed decision-making by owners end up in lower performance and higher costs in carrying out projects (Ghoddousi \& Hosseini, 2012). In this study, owner's records are conceptualized in a probabilistic form of project cost and/or schedule failure (overrun) obtained from past projects, to 
facilitate contractors in quantifying the level of the risk associated with the factors above. The probabilities of cost and schedule overruns can be estimated through the bestfit probability distribution functions (PDF) for actual and estimated cost and time for project completion.

\subsection{Technique selection}

Within the context of reliability analysis, the probability of failure is shown shaded in Figure 1. With reference to Eqn (2), where, $Q$ and $R$ are normally distributed, the reliability index $\beta$ is estimated through Eqn (6), where the symbol $\mu$ is the mean and $\sigma$ is the corresponding standard deviation of normal variables. In some practical cases $Q$ and/or $R$ deviate from a normal distribution. In such cases, the Rackwitz-Fiessler iterative technique can be applied in estimating $\beta$ (Nowak \& Collins, 2000; Ghodoosi et al., 2015, 2016). The Rackwitz-Fiessler iterative method is adopted to estimate the reliability index and the corresponding probability of project failure in this study.

$$
\beta=\frac{\mu_{R}-\mu_{Q}}{\sqrt{\sigma_{R}^{2}+\sigma_{Q}^{2}}} .
$$

The Rackwits-Fiessler iterative technique is based on normal approximation of non-normal distributions (equivalent normal distribution) for system resistance $R$ and load $Q$ at the most probable failure point. Tung et al. (2006) presented a table that contains normal transformation of non-normal distributions often applied in reliability analysis. The equivalent normal variables of lognormal and exponential distributions needed in this study are illustrated in Appendix 1. The procedure for normal approximation of three-parameter lognormal distribution does not exist in the literature, hence, the corresponding equivalent normal mean and standard deviation values here are estimated according to the process described in Appendix 2.

The most probable failure point $\left(X^{*}\right)$ is defined as the point of maximum failure probability on the limit state function (i.e. $g=R-Q=0, X^{*}$ is located on the failure boundary). Since $X^{*}$ is not always defined as an a priori, an iteration technique can be adopted to estimate the reliability index. In cases where $Q$ and/or $R$ are not normally distributed, the reliability index is estimated by replacing the equivalent normal mean, $\mu^{e}$, and standard deviation, $\sigma^{e}$, values in Eqn (6) at the most probable failure point $\left(X^{*}\right)$, which yields Eqn (7). Next, the new $Q^{*}$ and/or $R^{*}$ are calculated through Eqns (8) and (9). The iteration process continues until those parameters do not deviate significantly from the last iteration. The reliability index $\beta$ is estimated through Eqn (7) for the last iteration. The process of estimating reliability index is expressed in Figure 2 in the form of a flow chart.

$$
\begin{aligned}
& \beta=\frac{\mu_{R}^{e}-\mu_{Q}^{e}}{\sqrt{\sigma_{R}^{e 2}+\sigma_{Q}^{e 2}}} ; \\
& R^{*}=\mu_{R}^{e}-\frac{\sigma_{R}^{e 2} \cdot \beta}{\sqrt{\sigma_{R}^{e 2}+\sigma_{Q}^{e 2}}} ; \\
& Q^{*}=\mu_{Q}^{e}+\frac{\sigma_{Q}^{e 2} \cdot \beta}{\sqrt{\sigma_{R}^{e 2}+\sigma_{Q}^{e 2}}} .
\end{aligned}
$$

After the reliability index is calculated, the probability of cost and/or time failure for a new project owned by the client is estimated as $P_{F}=\Phi(-\beta)$, as defined in Eqn (5). Contractor is usually responsible for the majority of risks involved in construction like quality problems, losses and delays due to improper means and methods of construction, poor productivity, labor strikes, construction plan changes and poor site safety (Smith \& Bohn, 1999). Owner's reputation in the form of project failure probability obtained from past projects assists construction managers in deciding whether to take such big responsibility and bid for a new project, avoid bidding by a no-bid decision, or adjust their bid pricing accordingly.

\subsection{Data acquisition}

In this study, data are obtained from the documented records of several completed projects. The dataset covers the actual/contract schedule and cost for 40 projects with the University of Isfahan (Iran) as the client, delivering projects with 30 different contactors. Having a pool of 30 different contractors was deemed an acceptable approach to minimize the impact of contractor-related factors and capturing distinctive characteristics of contractors in the sample. Contractors are selected from a bigger statistical population where contractor selection processes and contract types are almost identical. All contracts were subject to open competitive tendering. In addition, project size, original contract cost and contract period for all 40 selected projects are in similar ranges, that is, applicable in small to medium contracts. The data on cost, time of completion, contract price and schedule of constructed projects are obtained from University of Isfahan Facilities Planning Office.

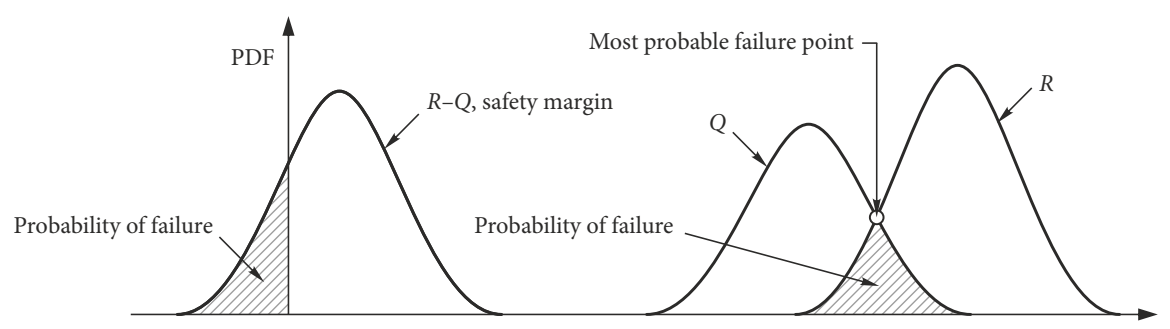

Figure 1. PDFs of $Q$ and $R$ and the probability of failure (adapted from Nowak \& Collins, 2000) 


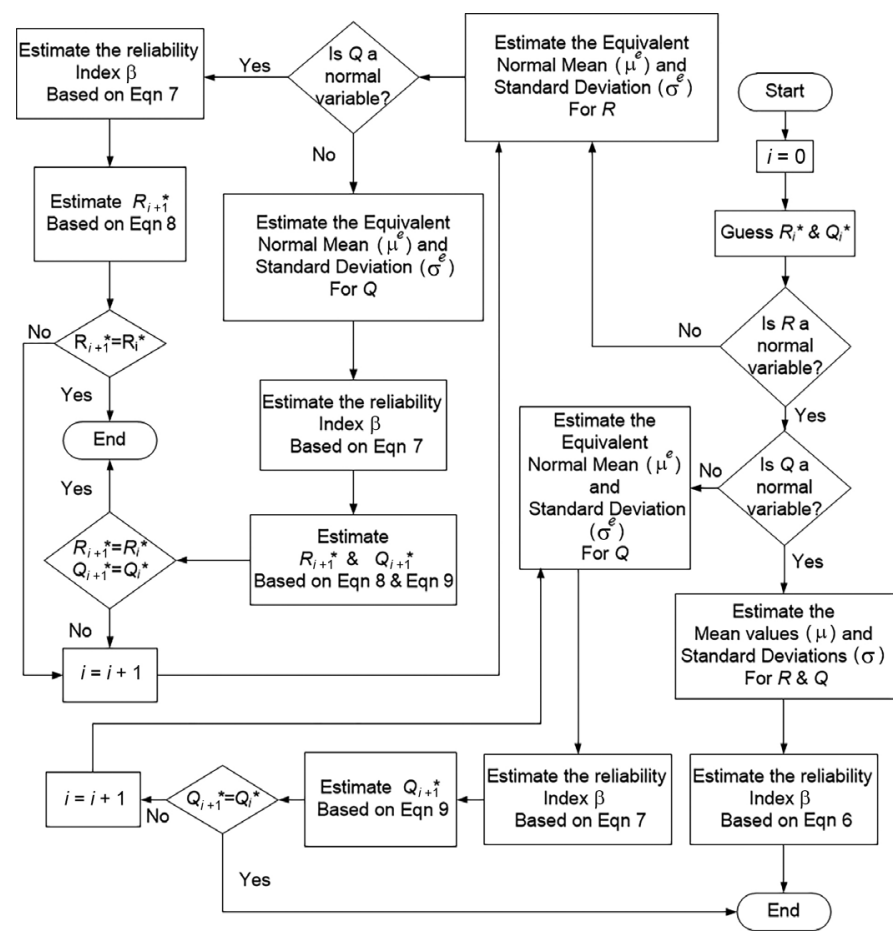

Figure 2. The iterative technique to calculate reliability index $\beta$ based on normal approximation of non-normal distributions

Founding the analysis and findings on such a dataset is considered as a justified approach, because where a small sample of projects is applied as a representative of the whole population, one can develop a reasonable theoretical and practical conclusion, provided that the sample approximates a much bigger population (Love et al., 2013). Moreover, there exist serious barriers in accessing such case studies and datasets. As Galway (2004) states, these barriers are typically concerned with 'classification, proprietary practices, and sensitivity to retrospective critical review of project management decisions', making commercial companies reluctant to support such research attempts.

\subsection{Process description}

Upon collecting the data, the best-fit probability distribution is estimated for each set of cost and schedule data, Figure 3. The Oracle Crystal Ball 11.1.1 as described by Ghodoosi et al. $(2015,2016)$ is applied to determine the best-fit cost and schedule distributions. Next, the iterative Rackwits-Fiessler reliability analysis is run on the actual and contract probability distributions and the reliability index is estimated accordingly. The probability of cost and/or schedule failure for a new project owned by the client is estimated through Eqn (5): $P_{F}=\Phi(-\beta)$.

With respect to contractor's responsibilities regarding the majority of construction risks, company's financial and logistic situation and owner's record in the form of probability of project failure $\left(P_{F}\right)$ are determinants of the way ahead. A contractor may decide to avoid bidding (no-bid decision), try to negotiate with the owner or adjust the bid pricing accordingly. This newly proposed process is straightforward, easy and rapid as compared to the existing analytical approaches available in the related literature.

\section{From data to findings}

The cost of risk is modeled as the probability of failure (cost or schedule overrun) multiplied by the impact thereof. Cost overrun is defined as the difference between a project's contract (bid) price and the actual construction cost. Based on this developed model and the records of previous projects owned by the client, contractor is able to quantify owner's reputation. A contractor may consider several scenarios. Frist, in the case of high rate of cost overrun, a contractor may avoid bidding for a new project with such client. Second, to be in the safe side, a contractor may bid for a new project based on the expected value of cost overrun; if the proposed bid is not won the contractor would have a rational justification. Finally, contractor realizes the high risk of working with such client and tries to apply negotiation techniques and construction technology modifications to minimize the costs as much as possible. In the case where the client is found to be reputable with a low probability of cost overrun, contractors are more flexible to lower the risk element of markup with more confident.

Alternatively, cumulative probability distribution could be applied in estimating the expected value of cost overrun within the introduced ranges. The expected value is calculated as the probability of cost overrun within a specific range multiplied by the maximum cost overrun corresponding to that range. Typical probability distribution function (PDF) and the corresponding cumulative distribution function (CDF) for cost overrun are illustrated in Figures 4 and 5, respectively. 


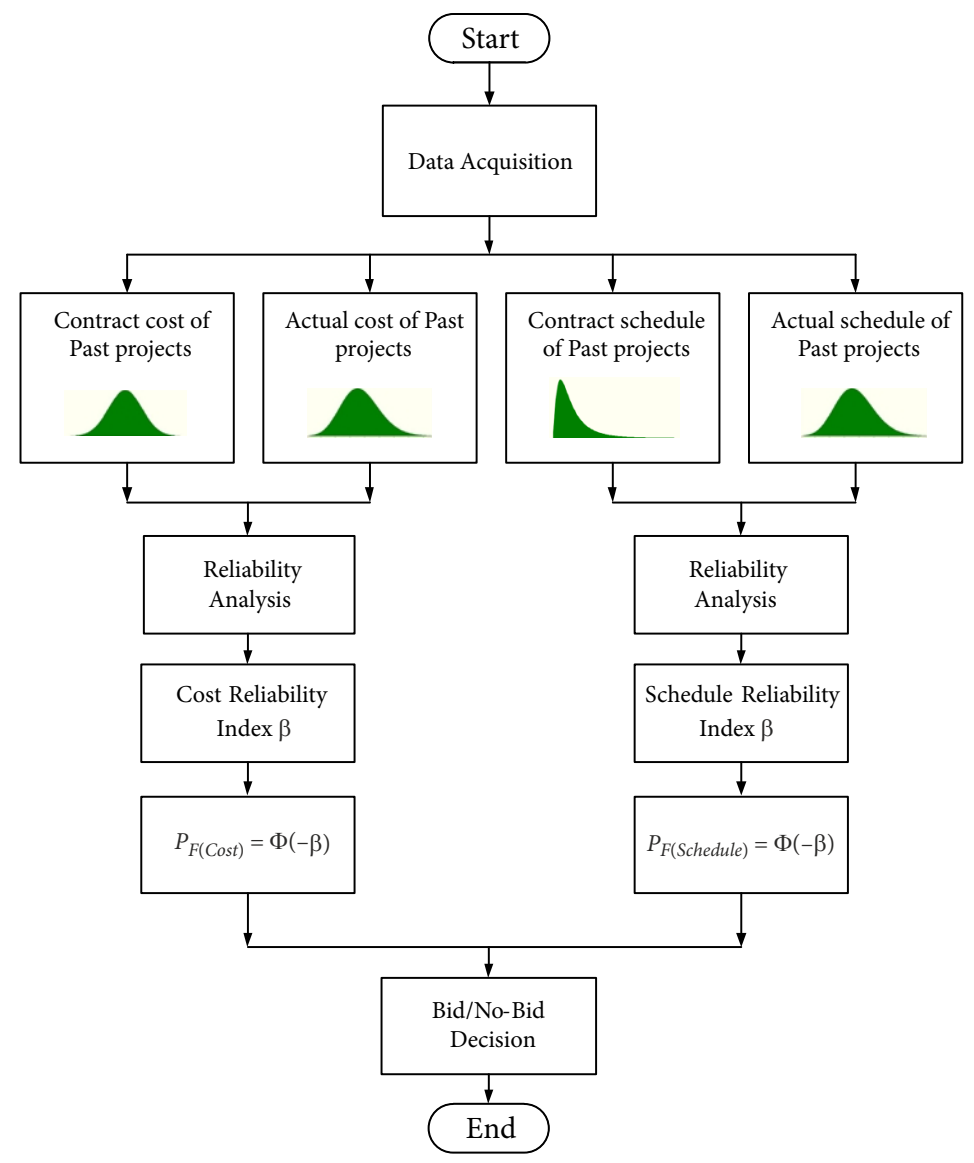

Figure 3. Bid/no-bid decision making based on reliability analysis

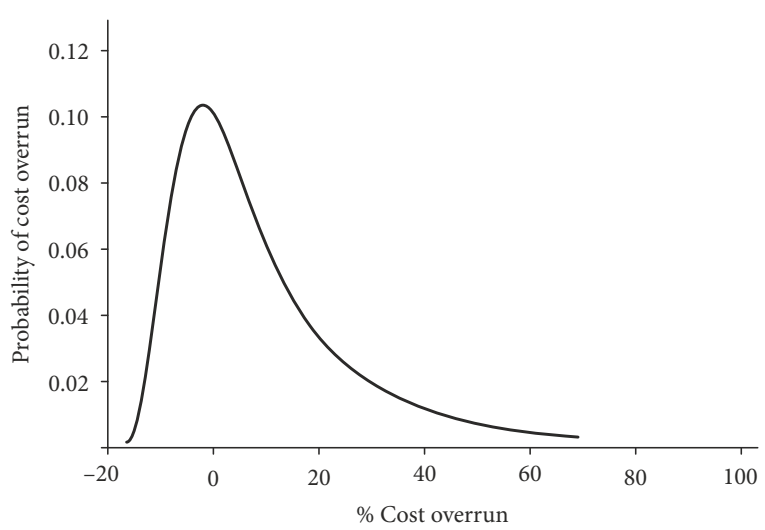

Figure 4. PDF for cost overruns

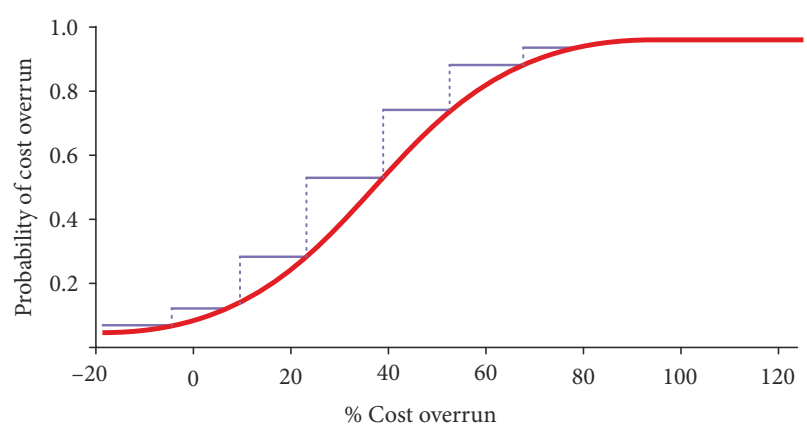

Figure 5. CDF for cost overruns
By subtracting the actual cost from the contract cost for the past projects owned by the client, a set of cost overrun data is acquired. The best fit continues PDF to the cost overrun, $f_{x}(x)$, is estimated through Oracle Crystal Ball 11.1.1. Next, the corresponding CDF of the cost overrun, $F_{x}(x)$, is yield through Eqn (10). The probability of cost overrun in $0<x<a$ range is estimated based on Eqn (11). Finally, the risk or expected value of cost overrun in that range is expressed through Eqn (12). The risk of schedule overrun is estimated in a similar manner.

$$
\begin{aligned}
& F_{x}(x)=\int_{-\infty}^{x} f_{x}(x) ; \\
& \int_{0}^{a} f_{x}(x)=F_{x}(a)-F_{x}(0) ;
\end{aligned}
$$

Risk of cost overrun $=\left\{F_{x}(a)-F_{x}(0)\right\} \times a$.

\section{Case study}

The best fit distributions to the actual and contract cost and schedule for 40 case-study projects executed by 30 different contractors are estimated trough Oracle Crystal Ball 11.1.1 (see Figure 6). As discussed, normal approximation of non-normal cost and schedule distributions are estimated according to Appendix 1. The reliability indices and the corresponding probabilities of cost and schedule failures (overruns) are calculated according to Table 1. 
Table 1. Reliability indices and probabilities of schedule and cost overrun for 40 case-study projects

\begin{tabular}{|l|c|c|}
\hline $\begin{array}{c}\text { Failure } \\
\text { type }\end{array}$ & $\begin{array}{c}\text { Reliability } \\
\text { index } \beta\end{array}$ & $\begin{array}{c}\text { Probability of failure } \\
P_{F}=\Phi(-\beta)\end{array}$ \\
\hline Project cost & 0.026 & 0.49 \\
\hline Project completion time & 0.38 & 0.35 \\
\hline
\end{tabular}

The obtained results indicate that the probabilities of cost and schedule overrun for projects are $49 \%$ and $35 \%$, respectively. This information assigns a value to the record of client/owner in terms of financial ability, payment record, decision-making capabilities, number of change orders and contract administration competency.

Managers should decide if they opt to bid for a project based on this newly proposed quantified owner's reputation and such a high rate of cost overrun. It is important to note that many parameters may influence schedule or cost overrun; however, by considering many projects of matching size, contract type, client sector and contractor selection process, client's performance and reputation becomes essential. In case the contractor decides to bid for a new project, to be in the safe side, contractor may add up to $49 \%$ to the estimated total cost and may bid for a new project; if the proposed bid is not won the contractor would have a rational justification. As mentioned, contractor may also realize the high risk of working with such client and try to apply negotiation techniques and construction technology modifications to minimize costs, as much as possible.

Alternatively, cost of risk can be estimated within ranges. The cost and schedule overruns PDF and CDF for

a)

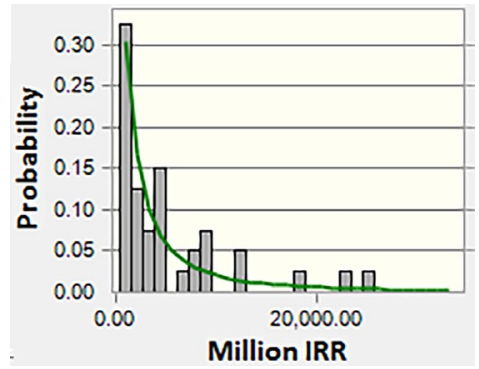

c)

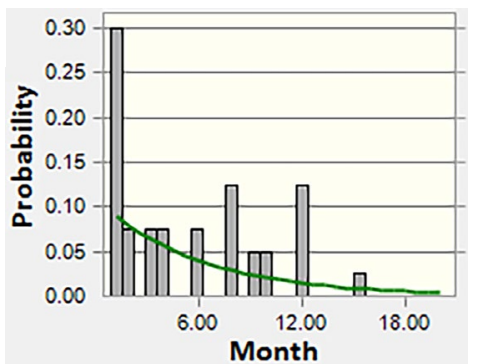

the set of 40 selected projects for which schedule and cost distributions as illustrated in Figure 6 are shown in Figure 7. Oracle Crystal Ball 11.1.1 has been used here to find the best-fit distributions to contract and actual cost for the sample of 40 projects. Figures $6 \mathrm{a}$ and $6 \mathrm{~b}$ demonstrate the best fit distributions to contract costs and actual costs for the sample of 40 university projects, respectively. And Figures $6 \mathrm{c}$ and $6 \mathrm{~d}$ show the best fit distributions to contract duration and the actual time between the commencement and termination of the same sample of projects.

The cost or schedule overrun data are acquired by subtracting the actual cost or time of project completion from those of the contract for all projects in the population. Next, the best-fit distributions are achieved using the already mentioned process. Figures $7 \mathrm{a}$ and $7 \mathrm{~b}$ respectively demonstrate the best fit PDF and CDF to cost overrun for the 40 projects, as discussed; whereas, Figures $7 \mathrm{c}$ and $7 \mathrm{~d}$ show the best fit PDF and CDF to schedule overrun or delay for the same sample of projects. Both Figures 6 and 7 are the results of Oracle Crystal Ball 11.1.1 distribution fitting. The cost of risk is estimated through Eqn (12) for different ranges of cost overrun.

\section{Model implementation}

The method developed in this study is implemented to estimate the bid price for a low-rise two-story building. Here, it is assumed that this $384 \mathrm{~m}^{2}$ building is to serve as a dormitory on the university premises, with the same owner/client associated with all previous 40 projects (source of data). The main structural system is masonry wall supported by a foundation system including strip

b)

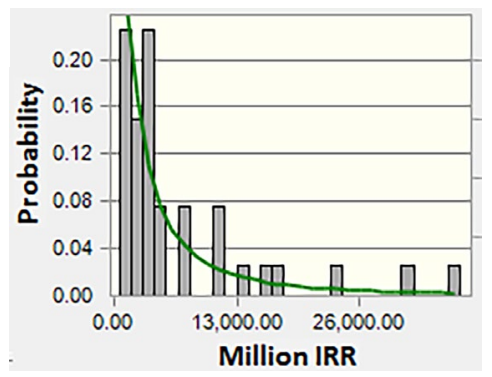

d)

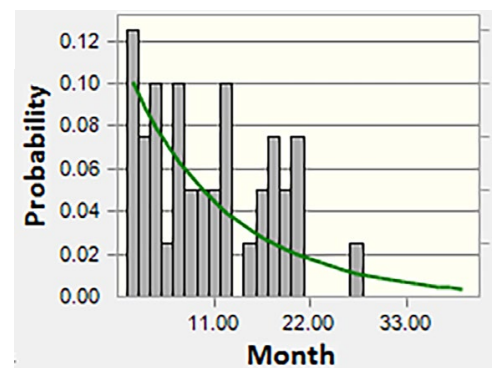

Figure 6. The best fit probability distributions for actual and contract cost and time: a - Best fit distribution for contract cost, lognormal with $\mu=8507.17, \sigma=2496$ and $\gamma=325.99 ; \mathrm{b}-$ Best fit distribution for actual cost, lognormal with $\mu=8972.48, \sigma=2173$ and $\gamma=325.02 ; c-$ Best fit distribution for contract completion time, exponential with $\lambda=0.17$; $\mathrm{d}-$ Best fit distribution for actual completion time, exponential with $\lambda=0.09$

Note: IRR - Iranian Rial; $\mu$ - mean; $\sigma$ - standard deviation; $\gamma$ - location; $\lambda$ - rate, US\$/IRR was close to 32400 in 2016. 
a)

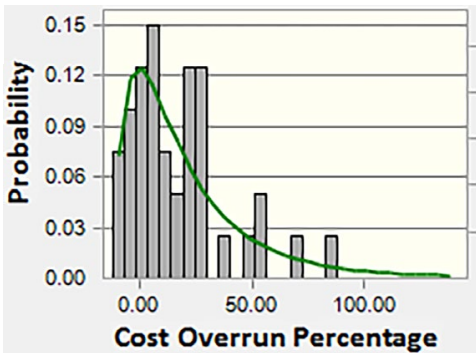

c)

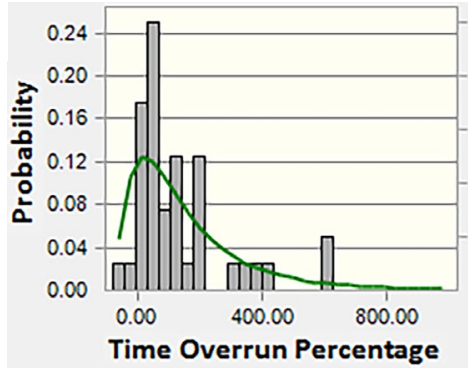

b)

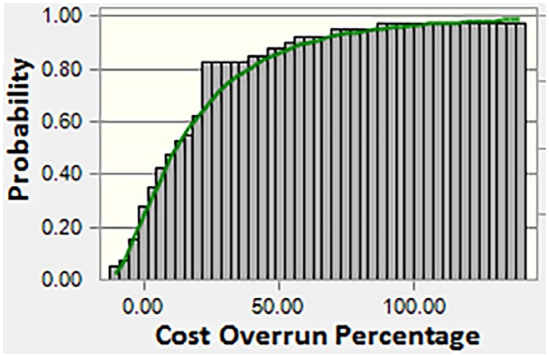

d)

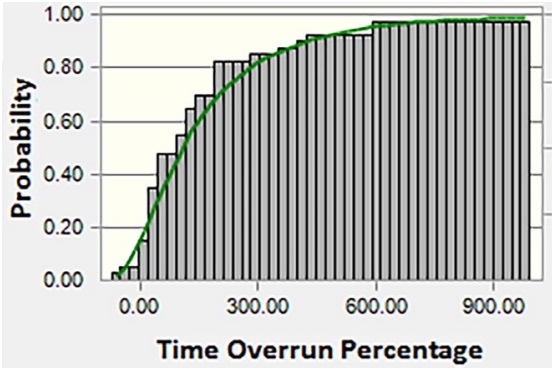

Figure 7. The best fit PDF and CDF for cost and schedule overrun: a - Best fit PDF for cost overrun, lognormal with $\mu=21.99, \sigma=34.97$ and $\gamma=17.33$; b - CDF for cost overrun; $c-$ Best fit PDF for schedule overrun, lognormal with $\mu=166.29, \sigma=217.5$ and $\gamma=104.9 ; \mathrm{d}-\mathrm{CDF}$ for schedule overrun

Note: $\mu$ - mean; $\sigma$ - standard deviation; $\gamma$ - location.

reinforced concrete anchors. Floor system is reinforced concrete joist and filler block and the facade is made of facing bricks. The total development cost including construction of the structural system, finishing, facade, roofing, internal cladding, utilities and thermal insulation plus the indirect costs is estimated to be $\$ 285 / \mathrm{m}^{2}$, in total $\$ 109,440$, within 18 months construction time (Zeynalian et al., 2012).

As discussed, probabilities of cost and time overrun for the projects owned by the client are $49 \%$ and 35\% respectively, Table 1. Provided that if a contractor decides to accept such level of client/owner's failure rate and bid for the project, the cost of risk is calculated based on the contractor's risk aversion and market competition. The cost of taking such a risk can be estimated as the $49 \%$ of estimated total cost. Alternatively, where the contractor aims to increase the chance of winning the bid, the cost of risk or expected value of cost overrun for different ranges could be estimated through Eqn (12), Table 2. Contractor decides the level of acceptable risk for the company and directly calculates the cost of such risk through the cost overrun cumulative distribution, Figure $7 \mathrm{~b}$. The risk of schedule overrun is estimated in a similar manner by using Eqn (12), meanwhile, the multiplier in this formula will be contract time. We added this sentence here for referring to Table 3.

The bid price is estimated in accordance with Eqn (1). As discussed, the amount of profit depends on the return a contractor expects on the project. To illustrate this, assume that based on market competition, the contractor decides to accept the risk of $20 \%$ cost overrun and expects
Table 2. Risk of cost overrun for the case study (Estimated cost: \$109,440)

\begin{tabular}{|c|c|c|}
\hline $\begin{array}{c}\text { Probability of } \\
\text { cost overrun } \\
(0-a) \%\end{array}$ & $\left\{F_{x}(a)-F_{x}(0)\right\}$ & $\begin{array}{c}\text { Risk of cost overrun }= \\
\left\{F_{x}(a)-F_{x}(0)\right\} \times a / 100 \times \\
\text { Estimated total cost }\end{array}$ \\
\hline $0-5$ & 0.09 & $\$ 480$ \\
\hline $0-10$ & 0.17 & $\$ 1918$ \\
\hline $0-15$ & 0.26 & $\$ 4223$ \\
\hline $0-20$ & 0.33 & $\$ 7251$ \\
\hline $0-25$ & 0.39 & $\$ 10859$ \\
\hline $0-30$ & 0.45 & $\$ 14918$ \\
\hline
\end{tabular}

Table 3. Risk of time overrun for the case study (Contract completion time: 18 months)

\begin{tabular}{|c|c|c|}
\hline $\begin{array}{c}\text { Probability of } \\
\text { time overrun } \\
(0-a) \%\end{array}$ & $\left\{F_{x}(a)-F_{x}(0)\right\}$ & $\begin{array}{c}\text { Risk of schedule overrun }= \\
\left\{F_{x}(a)-F_{x}(0)\right\} \times a / 100 \times \\
\text { Contract time }\end{array}$ \\
\hline $0-10$ & 0.02 & 0.04 month \\
\hline $0-20$ & 0.05 & 0.17 month \\
\hline $0-30$ & 0.07 & 0.39 month \\
\hline $0-40$ & 0.1 & 0.71 month \\
\hline $0-50$ & 0.12 & 1.12 month \\
\hline
\end{tabular}

$5 \%$ profit on the project, then the bid price based on the projects' record owned by the client and for the case-study project would be:

Bid price $=\$ 109,440+\$ 7,251+0.05 \times \$ 109,440=$ $\$ 122,163$. 


\section{Practical implications}

As discussed in brief, the process and approach proposed here will be of direct appeal to construction companies and estimators involved in bid decision-making. That is, when bidding for a new project, a contractor should consider its financial situation, current workload of the company, market situation and managers' risk aversion. Accordingly, many factors affect the decision-making process, leaving decision makers with a multifaceted complicated matter of concern (Awwad, 2016). The methodology proposed here simplifies the problem for contractors. That is, client/owner record is treated as a reflector of what happened in the past projects to quantify the risks associated in working with this client/owner. This gives decision makers a simple criterion for decision making in bid/nobid decision-making, Figure 3. Through a simple calculation, construction companies can avoid losing money on complicated bid/no-bid decision making procedures, a problem that currently affects contractors in the construction industry (Vilutienè \& Zavadskas, 2003; Hwang \& Kim, 2016).

This study provides a background for addressing the problems of "overcomplicated existing solutions", "lack of data" and "tight scheduling" for bid pricing, as pointed out by Ballesteros-Pérez et al. (2014). According to the proposals of this study, based on the data acquired from the past projects and running reliability analysis, the probabilities of cost and schedule overruns are calculated simply as quantitative values. This gives practitioners an insight as to the potential of failure and informs subsequent steps in the bid decision-making process.

When a contractor is confident that the lowest possible price is proposed, if the proposed bid is not won the contractor would have a rational justification. Besides, the outcome directs contractors towards implementing the best options available to encounter the potential failure rate.

\section{Conclusions}

This study stands out among other research studies of its kind in view of addressing two major issues: first, existing analytical models are found to be too data-driven, time consuming and complicated for estimators and managers; second, existing models do not address the actual risk allocation process applied by contractors during the tender preparation. These facts indicate that the main benefit of applying this developed method in bid decision-making process is its being easy, rapid and applicable by practitioners who are trained with the basics of probability and statistics. The developed risk analysis model is dynamic by nature, that is, it can be applied to any type of project where different levels of risk and probability of failure are involved. Moreover, this newly proposed method is flexible in terms of project size, original contract cost and the contract period.
In theoretical sense, this developed method offers a new procedure for allocating schedule and cost overrun risks to bid decision-making process, where reliability analysis and theory of probability and statistics are applied. This innovative combination would assist managers in bid/no-bid decision and estimating a reasonable competitive bid price where client's record and financial ability, record of projects owned by the client, format of the contract and tender documents, payment regularity, scope of work, competition and contractors' technical capability are of concern. From another vantage point, findings of the study provide a springboard for calculating and estimating contingency in construction projects. That is, the concept of reliability analysis is borrowed from another field, to be used in the construction context in terms of enabling calculating time and costs contingencies for construction activities. The case discussed here provides a practical model, to be taken as a blueprint for estimating contingencies.

Despite the contributions of this study, several limitations are to be acknowledged. Cost overruns or schedule delays on previous projects can be stemmed from contractors' or subcontractors' actions, which logically should be considered alongside owner's reputation in bid decisionmaking. In this study, however, owner's records are conceptualized in a probabilistic form of project cost and/ or schedule failure (overrun), obtained from a set of 40 projects executed by 30 different contractors. Given the diversity of contractors, application of owner's reputation as the main factor for quantifying the level of the risk is justified. That said, this is still a limitation of the study that remains to be addressed in future studies on the topic. Consideration of other factors that affect bid decisions, including uncertainty of bidding documents, or experience and management skills of contractors can be combined with owners' reputation to enhance the proposed method, as a fertile ground for further research into the topic.

Here, the failure risks of bid cost and schedule are analyzed in an independent manner, however, cost and schedule overruns are correlated, representing another limitation of the present study. Consequently, there is need for a more comprehensive model where any correlation between cost and schedule overruns would be of major concern. Besides, applicability of this method is affected by the lack of access to clients/owners' records in more detail. The reasons might be issues of classification, proprietary practices, and sensitivity to retrospective critical review of project management decisions. More quantitative studies are required in this area to convince the industry of the necessity and usefulness of such risk evaluation techniques.

The proposed model can be considered as a starting point that can be coupled with other probabilistic models to come up with a more comprehensive bid decision support tool, as another area for future research. which consider historical bidding experience or patterns of competi- 
tors. Such combination could be a powerful tool that can support more objective bid decision makings. Moreover, findings of the present study provide another research opportunity for future researchers, that is, validating the proposed model through presenting it to practitioners and experts in the construction remains to be an objective for future enquiries.

\section{Author contributions}

Mehran ZEYNALIAN was responsible for collecting, preparing, and cleaning the datasets. Farzad GHODOOSI and Ashutosh BAGCHI added the theoretical principles and analyzed the data, along with adding the findings to the manuscript and revising the work. M. Reza HOSSEINI and Tatjana VILUTIENE were responsible for writing up the review of the literature and discussion on the findings, along with contributing to revising the manuscript.

\section{Disclosure statement}

Authors have no competing financial, professional, or personal interests from other parties related to this research study.

\section{References}

Alsharqawi, Y. (2016). Cost planning strategy in bidding stage using 5D BIM. Eastern Mediterranean University (EMU)-Doğu Akdeniz Üniversitesi (DAÜ).

Asgari, S., Awwad, R., Kandil, A., \& Odeh, I. (2016). Impact of considering need for work and risk on performance of construction contractors: An agent-based approach. Automation in Construction, 65, 9-20.

https://doi.org/10.1016/j.autcon.2016.01.004

Aven, T., \& Zio, E. (2011). Some considerations on the treatment of uncertainties in risk assessment for practical decision making. Reliability Engineering \& System Safety, 96(1), 64-74. https://doi.org/10.1016/j.ress.2010.06.001

Awwad, R. (2016). Evolutionary simulation of contractors' learning and behavior under two bid-tendering approaches. Journal of Management in Engineering, 32(2), 04015041. https://doi.org/10.1061/(ASCE)ME.1943-5479.0000400

Awwad, R., \& Ammoury, M. (2019). Owner's perspective on evolution of bid prices under various price-driven bid selection methods. Journal of Computing in Civil Engineering, 33(2), 04018061.

https://doi.org/10.1061/(ASCE)CP.1943-5487.0000803

Aznar, B., Pellicer, E., Davis, S., \& Ballesteros-Pérez, P. (2017). Factors affecting contractor's bidding success for international infrastructure projects in Australia. Journal of Civil Engineering and Management, 23(7), 880-889.

https://doi.org/10.3846/13923730.2017.1341955

Ballesteros-Pérez, P., González-Cruz, M. C., \& Cañavate-Grimal, A. (2013). On competitive bidding: Scoring and position probability graphs. International Journal of Project Management, 31(3), 434-448.

https://doi.org/10.1016/j.ijproman.2012.09.012

Ballesteros-Pérez, P., González-Cruz, M. C., Fernández-Diego, M., \& Pellicer, E. (2014). Estimating future bidding performance of competitor bidders in capped tenders. Journal of Civil Engineering and Management, 20(5), 702-713.

https://doi.org/10.3846/13923730.2014.914096
Ballesteros-Pérez, P., \& Skitmore, M. (2016). Estimating the number of new and repeated bidders in construction auctions. Construction Management and Economics, 34(12), 919934. https://doi.org/10.1080/01446193.2016.1231408

Biruk, S., Jaśkowski, P., \& Czarnigowska, A. (2017). Modelling contractor's bidding decision. Ekonomia i Zarzadzanie, 9(1), 64-73. https://doi.org/10.1515/emj-2017-0007

Carr, R. I. (1982). General bidding model. Journal of the Construction Division, 108(4), 639-650.

Chao, L. C. (2007). Fuzzy logic model for determining minimum bid markup. Computer-Aided Civil and Infrastructure Engineering, 22(6), 449-460. https://doi.org/10.1111/j.1467-8667.2007.00500.x

Cheng, M.-Y., Hsiang, C.-C., Tsai, H.-C., \& Do, H.-L. (2011). Bidding decision making for construction company using a multi-criteria prospect model. Journal of Civil Engineering and Management, 17(3), 424-436.

https://doi.org/10.3846/13923730.2011.598337

Chileshe, N., Kavishe, N., \& Edwards, D. J. (2020). Critical factors influencing the bid or no-bid decision of the indigenous small building contractors in Tanzania. Construction Innovation. https://doi.org/10.1108/CI-09-2019-0098

Chou, J.-S., Pham, A.-D., \& Wang, H. (2013). Bidding strategy to support decision-making by integrating fuzzy AHP and regression-based simulation. Automation in Construction, 35, 517-527. https://doi.org/10.1016/j.autcon.2013.06.007

Chua, D., \& Li, D. (2000). Key factors in bid reasoning model. Journal of Construction Engineering and Management, 126(5), 349-357.

https://doi.org/10.1061/(ASCE)0733-9364(2000)126:5(349)

Chua, D., Li, D., \& Chan, W. (2001). Case-based reasoning approach in bid decision making. Journal of Construction Engineering and Management, 127(1), 35-45.

https://doi.org/10.1061/(ASCE)0733-9364(2001)127:1(35)

Duzkale, A. K., \& Lucko, G. (2016a). Exposing uncertainty in bid preparation of steel construction cost estimating: I. Conceptual framework and qualitative CIVIL classification. Journal of Construction Engineering and Management, 142(10), 04016049.

https://doi.org/10.1061/(ASCE)CO.1943-7862.0001117

Duzkale, A. K., \& Lucko, G. (2016b). Exposing uncertainty in bid preparation of steel construction cost estimating: II. Comparative analysis and quantitative CIVIL classification. Journal of Construction Engineering and Management, 142(10), 04016050 .

https://doi.org/10.1061/(ASCE)CO.1943-7862.0001124

Egemen, M., \& Mohamed, A. N. (2007). A framework for contractors to reach strategically correct bid/no bid and mark-up size decisions. Building and Environment, 42(3), 1373-1385. https://doi.org/10.1016/j.buildenv.2005.11.016

El-Mashaleh, M. S. (2010). Decision to bid or not to bid: a data envelopment analysis approach. Canadian Journal of Civil Engineering, 37(1), 37-44. https://doi.org/10.1139/L09-119

Elghaish, F., Abrishami, S., Hosseini, M. R., \& Abu-Samra, S. (2020). Revolutionising cost structure for integrated project delivery: a BIM-based solution. Engineering, Construction and Architectural Management.

https://doi.org/10.1108/ECAM-04-2019-0222

Galway, L. (2004). Quantitative risk analysis for project management. RAND Corporation. http://www.rand.org/pubs/working_papers

Ghoddousi, P., \& Hosseini, M. R. (2012). A survey of the factors affecting the productivity of construction projects in Iran. Technological and Economic Development of Economy, 18(1), 99-116. https://doi.org/10.3846/20294913.2012.661203 
Ghodoosi, F., Bagchi, A., \& Zayed, T. (2015). System-level deterioration model for reinforced concrete bridge decks. Journal of Bridge Engineering, 20(5), 04014081.

https://doi.org/10.1061/(ASCE)BE.1943-5592.0000670

Ghodoosi, F., Bagchi, A., \& Zayed, T. (2016). Reliability-based condition assessment of an externally restrained bridge deck system considering uncertainties in key design parameters. Journal of Performance of Constructed Facilities, 30(1), 04014189.

https://doi.org/10.1061/(ASCE)CF.1943-5509.0000699

Hosseini, M. R., Banihashemi, S., Chileshe, N., Namzadi, M. O., Udeaja, C., Rameezdeen, R., \& McCuen, T. (2016). BIM adoption within Australian Small and Medium-sized Enterprises (SMEs): an innovation diffusion model. Construction Economics and Building, 16(3), 71-86.

https://doi.org/10.5130/AJCEB.v16i3.5159

Hu, X., Xia, B., Skitmore, M., \& Chen, Q. (2016). The application of case-based reasoning in construction management research: An overview. Automation in Construction, 72, 65-74. https://doi.org/10.1016/j.autcon.2016.08.023

Hwang, J.-S., \& Kim, Y.-S. (2016). A bid decision-making model in the initial bidding phase for overseas construction projects. KSCE Journal of Civil Engineering, 20(4), 1189-1200. https://doi.org/10.1007/s12205-015-0760-y

Johansson, J., Hassel, H., \& Zio, E. (2013). Reliability and vulnerability analyses of critical infrastructures: Comparing two approaches in the context of power systems. Reliability Engineering \& System Safety, 120, 27-38.

https://doi.org/10.1016/j.ress.2013.02.027

Kitchenham, B., Pickard, L. M., Linkman, S., \& Jones, P. W. (2003). Modeling software bidding risks. IEEE Transactions on Software Engineering, 29(6), 542-554.

https://doi.org/10.1109/TSE.2003.1205181

Laryea, S., \& Hughes, W. (2008). How contractors price risk in bids: theory and practice. Construction Management and Economics, 26(9), 911-924.

https://doi.org/10.1080/01446190802317718

Laryea, S., \& Hughes, W. (2011). Risk and price in the bidding process of contractors. Journal of Construction Engineering and Management, 137(4), 248-258.

https://doi.org/10.1061/(ASCE)CO.1943-7862.0000293

Leśniak, A. (2015). Reliability assessment of research into contractors' bidding decisions. Procedia Engineering, 122, 251257. https://doi.org/10.1016/j.proeng.2015.10.033

Leśniak, A., \& Plebankiewicz, E. (2015). Modeling the decisionmaking process concerning participation in construction bidding. Journal of Management in Engineering, 31(2), 04014032. https://doi.org/10.1061/(ASCE)ME.1943-5479.0000237

Li, G., Zhang, G., Chen, C., \& Martek, I. (2020). Empirical bid or no bid decision process in international construction projects: Structural equation modeling framework. Journal of Construction Engineering and Management, 146(6), 04020050. https://doi.org/10.1061/(ASCE)CO.1943-7862.0001830

Ling, F. Y. Y., \& Liu, M. (2005). Factors considered by successful and profitable contractors in mark-up size decision in Singapore. Building and Environment, 40(11), 1557-1565. https://doi.org/10.1016/j.buildenv.2004.12.001

Love, P. E., Sing, C., Wang, X., Edwards, D. J., \& Odeyinka, H. (2013). Probability distribution fitting of schedule overruns in construction projects. Journal of the Operational Research Society, 64(8), 1231-1247. https://doi.org/10.1057/jors.2013.29

Nowak, A. S., \& Collins, K. R. (2000). Reliability of structures. McGraw-Hill.
Owusu, E. K., Chan, A. P., Hosseini, M. R., \& Nikmehr, B. (2020). Assessing procurement irregularities in the supply-chain of Ghanaian construction projects: a soft-computing approach. Journal of Civil Engineering and Management, 26(1), 66-82. https://doi.org/10.3846/jcem.2020.11659

Russell, J. S., \& Jaselskis, E. J. (1992). Predicting construction contractor failure prior to contract award. Journal of Construction Engineering and Management, 118(4), 791-811. https://doi.org/10.1061/(ASCE)0733-9364(1992)118:4(791)

Shokri-Ghasabeh, M., \& Chileshe, N. (2016). Critical factors influencing the bid/no bid decision in the Australian construction industry. Construction Innovation, 16(2), 127-157. https://doi.org/10.1108/CI-04-2015-0021

Singh, V. P., Jain, S. K., \& Tyagi, A. K. (2007). Risk and reliability analysis: a handbook for civil and environmental engineers. American Society of Civil Engineers (ASCE). https://doi.org/10.1061/9780784408919

Smith, G. R., \& Bohn, C. M. (1999). Small to medium contractor contingency and assumption of risk. Journal of Construction Engineering and Management, 125(2), 101-108. https://doi.org/10.1061/(ASCE)0733-9364(1999)125:2(101)

Sonmez, R., \& Sözgen, B. (2017). A support vector machine method for bid/no bid decision making. Journal of Civil Engineering and Management, 23(5), 641-649. https://doi.org/10.3846/13923730.2017.1281836

Su, L., Wang, T., Li, H., Chao, Y., \& Wang, L. (2020). Multi-criteria decision making for identification of unbalanced bidding. Journal of Civil Engineering and Management, 26(1), 43-52. https://doi.org/10.3846/jcem.2019.11568

Tung, Y.-K., Yen, B.-C., \& Melching, C. (2006). Hydrosystems engineering reliability assessment and risk analysis. McGraw Hill.

Urquhart, S., \& Whyte, A. (2018). Contractor tendering research: going beyond bid/no-bid and markup models. Proceedings of the Institution of Civil Engineers-Management, Procurement and Law, 170(6), 255-262. https://doi.org/10.1680/jmapl.17.00039

Vilutienè, T., \& Zavadskas, E. K. (2003). The application of multicriteria analysis to decision support for the facility management of a residential district. Journal of Civil Engineering and Management, 9(4), 241-252. https://doi.org/10.1080/13923730.2003.10531335

Wanous, M., Boussabaine, H. A., \& Lewis, J. (2003). A neural network bid/no bid model: the case for contractors in Syria. Construction Management and Economics, 21(7), 737-744. https://doi.org/10.1080/0144619032000093323

Yazdani, M., Wen, Z., Liao, H., Banaitis, A., \& Turskis, Z. (2019). A grey combined compromise solution (COCOSO-G) method for supplier selection in construction management. Journal of Civil Engineering and Management, 25(8), 858-874. https://doi.org/10.3846/jcem.2019.11309

Ye, K., Shen, L., Xia, B., \& Li, B. (2014). Key attributes underpinning different markup decision between public and private projects: A China study. International Journal of Project Management, 32(3), 461-472.

https://doi.org/10.1016/j.ijproman.2013.06.001

Zeynalian, M., Trigunarsyah, B., \& Ronagh, H. R. (2012). Modification of advanced programmatic risk analysis and management model for the whole project life cycle's risks. Journal of Construction Engineering and Management, 139(1), 51-59. https://doi.org/10.1061/(ASCE)CO.1943-7862.0000571

Zio, E. (2009). Reliability engineering: Old problems and new challenges. Reliability Engineering \& System Safety, 94(2), 125-141. https://doi.org/10.1016/j.ress.2008.06.002 


\section{APPENDIX}

Appendix 1. Normal transformation of non-normal distributions

\begin{tabular}{|c|c|c|c|}
\hline 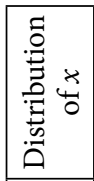 & PDF, $f_{x}\left(x^{*}\right)$ & Equivalent normal mean, $\mu_{x}^{e}$ & $\begin{array}{c}\text { Equivalent normal standard } \\
\text { deviation, } \sigma_{x}^{e}\end{array}$ \\
\hline 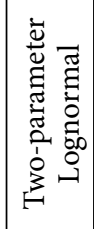 & $\frac{1}{\sqrt{2 \pi} x^{*} \sigma_{\ln x}} \exp \left\{-\frac{1}{2}\left[\frac{\ln \left(x^{*}\right)-\mu_{\ln x}}{\sigma_{\ln x}}\right]^{2}\right\}$ & $\begin{array}{c}x^{*}\left[1-\ln \left(x^{*}\right)+\mu_{\ln x}\right] \\
\text { where } \\
\mu_{\ln x}=\ln \left(\mu_{x}\right)\end{array}$ & $\begin{array}{c}x^{*} \sigma_{\ln x} \\
\text { where } \\
\sigma_{\ln x}=\sqrt{\ln \left[1+\frac{\sigma_{x}^{2}}{\mu_{x}^{2}}\right]}\end{array}$ \\
\hline 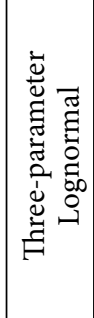 & $\frac{1}{\sqrt{2 \pi}\left(x^{*}-\gamma\right) \sigma_{\ln (x-\gamma)}} \exp \left\{-\frac{1}{2}\left[\frac{\ln \left(x^{*}-\gamma\right)-\mu_{\ln (x-\gamma)}}{\sigma_{\ln (x-\gamma)}}\right.\right.$ & $\begin{array}{c}x^{*}-\left(x^{*}-\gamma\right)\left[\ln \left(x^{*}-\gamma\right)-\mu_{\ln (x-\gamma)}\right] \\
\text { where } \\
\mu_{\ln (x-\gamma)}=\ln \left(\mu_{(x-\gamma)}\right) \\
\mu_{(x-\gamma)}=\mu_{x}-\gamma\end{array}$ & $\begin{array}{c}\left(x^{*}-\gamma\right) \sigma_{\ln (x-\gamma)}, \\
\text { where } \\
\sigma_{\ln (x-\gamma)}=\sqrt{\ln \left[1+\frac{\sigma_{(x-\gamma)}^{2}}{\mu_{(x-\gamma)}^{2}}\right]} \\
\sigma_{(x-\gamma)}=\sigma_{x}\end{array}$ \\
\hline 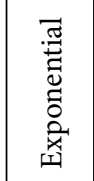 & $\lambda e^{-\lambda\left(x^{*}\right)} x>0$ & $\begin{aligned} x^{*}-z_{x^{*}}^{e} \times \sigma_{x^{*}}^{e} & \\
& \text { where } \\
z_{x^{*}}^{e}= & \Phi^{-1}\left[1-e^{-\lambda\left(x^{*}\right)}\right]\end{aligned}$ & $\frac{1}{\lambda \sqrt{2 \pi}} \exp \left\{-\frac{z_{x^{*}}^{e}}{2}+\lambda x^{*}\right\}$ \\
\hline
\end{tabular}

\section{Appendix 2. Three-parameter lognormal distribution}

Three-parameter lognormal distribution is a skewed distribution for modeling continuous random variable $Y=\ln (x-y)$. If $Y$ is distributed normally then $(x-y)$ and consequently $x$ is a lognormal variable. The lognormal random variable is defined for positive values of $x-y>0$; in other words, $x \in[\gamma, \infty)$. The probability density function, $\left[f_{x}(x)\right]$, is the first derivative of the cumulative distribution function, $\left[F_{x}(x)\right]$. The PDF and CDF could be estimated using the corresponding standard normal variables $\varnothing(Z)$ and $\Phi(Z)$ for the standard normal variable $Z$, where, $\varnothing$ is the standard normal distribution function and $\Phi$ is the corresponding cumulative standard normal distribution function.

$$
\begin{aligned}
& F_{x}\left(x^{*}\right)=P\left(x \leq x^{*}\right)=P\left(x-\gamma \leq x^{*}-\gamma\right)=P\left[\ln (x-\gamma) \leq \ln \left(x^{*}-\gamma\right)\right]=P\left(Y \leq Y^{*}\right)=F_{Y}\left(Y^{*}\right) ; \\
& F_{x}\left(x^{*}\right)=F_{Y}\left(Y^{*}\right)=\Phi\left(\frac{Y^{*}-\mu_{Y}}{\sigma_{Y}}\right)=\Phi\left(\frac{\left.\ln \left(x^{*}-\gamma\right)-\mu_{\ln (x-\gamma)}\right) ;}{\sigma_{\ln (x-\gamma)}}\right) \\
& f_{x}\left(x^{*}\right)=\frac{d}{d x} F_{x}\left(x^{*}\right)=\frac{d}{d x} \Phi\left(\frac{\ln \left(x^{*}-\gamma\right)-\mu_{\ln (x-\gamma)}}{\sigma_{\ln (x-\gamma)}}\right)=\frac{1}{\left(x^{*}-\gamma\right) \sigma_{\ln (x-\gamma)}} \varnothing\left(\frac{\ln \left(x^{*}-\gamma\right)-\mu_{\ln (x-\gamma)}}{\sigma_{\ln (x-\gamma)}}\right) ;
\end{aligned}
$$

or

$$
f_{x}(x)=\frac{1}{\sqrt{2 \pi}(x-\gamma) \sigma_{\ln (x-\gamma)}} \exp \left\{-\frac{1}{2}\left[\frac{\ln (x-\gamma)-\mu_{\ln (x-\gamma)}}{\sigma_{\ln (x-\gamma)}}\right]^{2}\right\} .
$$

The symbol $\mu$ is the mean and $\sigma$ is the corresponding standard deviation, where $\gamma$ is the location or shift of the corresponding lognormal variable. The distribution becomes the two-parameter lognormal distribution when $\gamma=0$.

Therefore,

$$
\varnothing\left(\frac{\ln \left(x^{*}-\gamma\right)-\mu_{\ln (x-\gamma)}}{\sigma_{\ln (x-\gamma)}}\right)=f_{x}\left(x^{*}\right)\left(x^{*}-\gamma\right) \sigma_{\ln (x-\gamma)},
$$


where

$$
\begin{gathered}
\sigma_{\ln (x-\gamma)}=\sqrt{\ln \left[1+\frac{\sigma_{(x-\gamma)}^{2}}{\mu_{(x-\gamma)}^{2}}\right]} ; \\
\mu_{\ln (x-\gamma)}=\ln \left(\mu_{(x-\gamma)}\right) ; \\
\sigma_{(x-\gamma)}=\sigma_{x} \text { and } \mu_{(x-\gamma)}=\mu_{x}-\gamma .
\end{gathered}
$$

\section{Normal approximation of three-parameter lognormal distribution}

In order to calculate the equivalent normal mean $\left(\mu_{x}^{e}\right)$ and standard deviation $\left(\sigma_{x}^{e}\right)$, the PDF and CDF of the threeparameter lognormal distribution are approximated to be equal to a normal CDF and PDF at the point $x^{*}$, respectively. For reliability analysis purposes the point $x^{*}$ is located on the failure boundary where $g=R-Q=0$.

$$
\begin{aligned}
& F_{x}\left(x^{*}\right)=\Phi\left(\frac{x^{*}-\mu_{x}^{e}}{\sigma_{x}^{e}}\right) ; \\
& f_{x}\left(x^{*}\right)=\frac{d}{d x} \Phi\left(\frac{x^{*}-\mu_{x}^{e}}{\sigma_{x}^{e}}\right)=\frac{1}{\sigma_{x}^{e}} \varnothing\left(\frac{x^{*}-\mu_{x}^{e}}{\sigma_{x}^{e}}\right) ; \\
& \mu_{x}^{e}=x^{*}-\sigma_{x}^{e}\left\{\Phi^{-1}\left[\left(F_{x}\left(x^{*}\right)\right]\right\} ;\right. \\
& \sigma_{x}^{e}=\frac{1}{f_{x}\left(x^{*}\right)} \varnothing\left(\frac{x^{*}-\mu_{x}^{e}}{\sigma_{x}^{e}}\right)=\frac{1}{f_{x}\left(x^{*}\right)} \varnothing\left\{\Phi^{-1}\left[\left(F_{x}\left(x^{*}\right)\right]\right\} .\right.
\end{aligned}
$$

For a three-parameter lognormal distribution:

$$
\begin{aligned}
& \sigma_{x}^{e}=\frac{1}{f_{x}\left(x^{*}\right)} \varnothing\left\{\Phi ^ { - 1 } \left[\Phi \left(\frac{\left.\left.\left.\ln \left(x^{*}-\gamma\right)-\mu_{\ln (x-\gamma)}\right)\right]\right\}=\frac{1}{\sigma_{\ln (x-\gamma)}\left(x^{*}\right)} \varnothing\left(\frac{\ln \left(x^{*}-\gamma\right)-\mu_{\ln (x-\gamma)}}{\sigma_{\ln (x-\gamma)}}\right) ;}{\sigma_{x}^{e}=\frac{1}{f_{x}\left(x^{*}\right)} f_{x}\left(x^{*}\right)\left(x^{*}-\gamma\right) \sigma_{\ln (x-\gamma)}=\left(x^{*}-\gamma\right) \sigma_{\ln (x-\gamma)} ;}\right.\right.\right. \\
& \mu_{x}^{e}=x^{*}-\left(x^{*}-\gamma\right) \sigma_{\ln (x-\gamma)}\left(\frac{\ln \left(x^{*}-\gamma\right)-\mu_{\ln (x-\gamma)}}{\sigma_{\ln (x-\gamma)}}\right) ; \\
& \mu_{x}^{e}=x^{*}-\left(x^{*}-\gamma\right)\left[\ln \left(x^{*}-\gamma\right)-\mu_{\ln (x-\gamma)] .}\right.
\end{aligned}
$$

